\title{
Equatorial electrojet in the East Brazil anomaly region
}

\author{
R. G. Rastogi ${ }^{1}$ and K. Yumoto ${ }^{2}$ \\ ${ }^{1}$ Physical Research Laboratory, Ahmedabad 380009, India \\ ${ }^{2}$ Department of Earth and Planetary Sciences, Kyushu University, 33, Fukuoka 812-858, Japan
}

(Received December 8, 2005; Revised August 9, 2006; Accepted August 30, 2006; Online published March 21, 2007)

\begin{abstract}
An examination of the geomagnetic field variations at equatorial stations in South America has shown that the daily range of the northward field, $\mathrm{H}$, is about $30 \%$ larger in Peru than in Brazil. The midday $\mathrm{H}$ field vector in Brazil shows a large westward tilt, corresponding to large westward declination at the station. A significant meridional trans-equatorial current system is suggested for the observed anomaly. The longitudinal variation in the equatorial electrojet current strength is suggested to be due to the corresponding variation in the ionospheric electric field rather than to the electrical conductivity.
\end{abstract}

Key words: Equatorial electrojet currents, longitudinal variation, meridional equatorial ionospheric current.

\section{Introduction}

Appleton (1946) described the two anomalies in the ionosphere at equatorial and low latitudes. He showed that the critical frequency of the $\mathrm{F}_{2}$ layer $\left(\mathrm{foF}_{2}\right)$ over the magnetic equator shows a minimum around the midday hours, and the latitudinal variation of noon values of $\mathrm{foF}_{2}$ shows a minimum over the magnetic equator and maxima around $15^{\circ} \mathrm{N}$ and $15^{\circ} \mathrm{S}$ dip latitudes. Chapman (1951) suggested that the equatorial enhancement of the daily range of the horizontal geomagnetic field $\mathrm{H}$ during the midday hours is due to a thin sheet of eastward flowing current in the E region of the ionosphere, which he named as the equatorial electrojet (EEJ). Baker and Martyn (1953) subsequently explained the EEJ as being due to the enhanced electrical conductivities over the equatorial ionosphere through the action of orthogonality of the electric and magnetic fields in a region of differing ion and electron mobility.

Rastogi (1959) explained the two anomalies in the $F_{2}$ region of the ionosphere at low latitudes as being due to the vertical uplift of the ionization by the $\mathrm{E} \times \mathrm{B}$ force over the magnetic equator and its subsequent transport to midlatitudes along the magnetic lines of force. Later, Rastogi (1961) found that the amplitude of lunar tidal variation in noon $F_{2}$ is enhanced over the magnetic equator in a manner similar to the latitudinal enhancement of the daily range of $\mathrm{H}$. It was found that the amplitude of lunar tide in $\mathrm{foF}_{2}$ was twofold larger in American longitudes than in Indian longitudes. It was suggested that the equatorial electrojet current may thus be stronger in American longitudes (Rastogi, 1962a).

The International Geophysical Year 1957-1958 saw the establishment of new geomagnetic observatories close to the magnetic equator at Addis-Ababa in Ethiopia, Trivandrum in India and Koror and Jarvis in the Pacific; this was

Copyright (c) The Society of Geomagnetism and Earth, Planetary and Space Sciences (SGEPSS); The Seismological Society of Japan; The Volcanological Society of Japan; The Geodetic Society of Japan; The Japanese Society for Planetary Sciences; TERRAPUB. in addition to the already existing one at Huancayo, Peru. Using the data from these observatories, Rastogi (1962b) showed that the longitudinal variation in the strength of the equatorial electrojet was strongest in American longitudes and weakest in Indian longitudes. The data also indicated that the strength of the equatorial electrojet is inversely related to the strength of the geomagnetic field. However, there have been no serious improvements in the distribution of the data available from the equatorial electrojet stations and a finer resolution of the longitudinal variation in the equatorial electrojet has not been possible. The region of eastern Brazil has been very abnormal in that the strength of the $\mathrm{H}$ field is minimum and the declination is maximum. Prof. K. Kitamura organized the establishment of fluxgate digital magnetometers at low latitudes around the world. We have chosen simultaneous data from Alcantra (ALC) and from Ancon (ANC) in Peru to estimate the equatorial electrojet current at the two ends of the vast South American sector. The coordinates of the two stations are given in Table 1.

The total intensity was almost the same at the two stations-26624 nT at Ancon and $26814 \mathrm{nT}$ at Alcantra. The inclination was $1.2^{\circ}$ at Ancon and $-0.02^{\circ}$ at Alcantra, but the declination was $1.5^{\circ} \mathrm{E}$ at Ancon and $20^{\circ} \mathrm{W}$ at $\mathrm{Al}-$ cantra. Thus, Alcantra is a unique equatorial electrojet station where the horizontal magnetic field vector is the most inclined from the geographic meridian. Our aim was to determine the effects of this situation on the direction and magnitude of the ionospheric current. The data for the present study were downloaded from the Quick Look maps in the website of the Kyushu University Equatorial Magnetometer chain. The original charts were digitally modified to obtain uniform scale values for the two stations, and a few selected periods were chosen for comparison.

\section{Results}

Figure 1 shows the northward, X, eastward, Y, and vertical, Z, fields at ANC and ALC during the period 11-21 
Table 1. Coordinates of Alcantra and Ancon stations.

\begin{tabular}{lcc}
\hline & Ancon (ANC) & Alcantra (ALC) \\
\hline Geog. Lat. $\left({ }^{\circ} \mathrm{S}\right)$ & 12.1 & 2.3 \\
Geog. Long. $\left({ }^{\circ} \mathrm{W}\right)$ & 77.0 & 44.4 \\
Geom. Lat $\left({ }^{\circ}\right)$ & 1.6 & 0.2 \\
Geom. Long $\left({ }^{\circ}\right)$ & 354.8 & 29.5 \\
Magnetic field X, nT & 26618 & 25143 \\
Magnetic field $\mathrm{Y}(\mathrm{nT})$ & 718 & -9318 \\
Magnetic field Z $(\mathrm{nT})$ & 55.1 & -9 \\
Inclination $\left(\mathrm{I}^{\circ}\right)$ & 1.2 & -0.02 \\
Declination $\left(\mathrm{D}^{\circ} \mathrm{E}\right)$ & 1.5 & -20.3 \\
Total intensity $(\mathrm{nT})$ & 26624 & 26814 \\
\hline
\end{tabular}
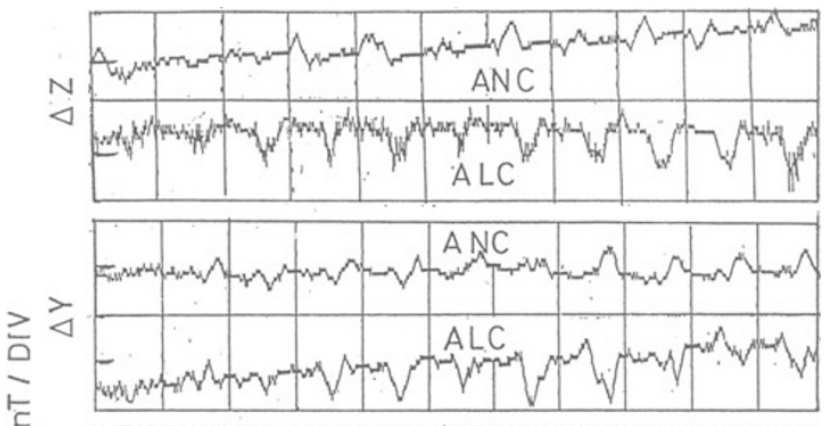

in

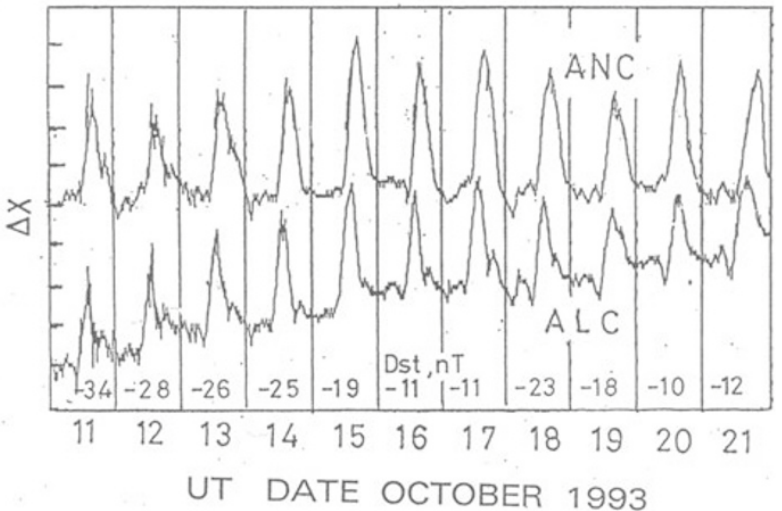

Fig. 1. Daily variations in the geomagnetic $\mathrm{X}, \mathrm{Y}$ and $\mathrm{Z}$ fields at Ancon (ANC) and Alcantra (ALC) during the period 11-21 October 1993.

October 1993. The charts are derived from high-resolution recordings and, therefore, the daily variations show shortperiod fluctuations superimposed on the smooth diurnal variations. The slow drift of the daily maps is due to the drift in the instrument and not due to the change in the mean strength of the magnetic field. The magnetic Ap indices are also shown in the figure, indicating that the period chosen was magnetically quiet. A cursory glance of the chart for $\mathrm{X}$ suggests a synchronous variation of the diurnal amplitude of the daily range at the two stations. A large value of range $\mathrm{X}$ on 15 October and a small value on 19 October can be seen at both stations. In terms of the daily variation of $\mathrm{Y}$ at ANC, the amplitudes are small, with a small maximum around local noon hours. The daily variations of Y at ALC show significant midday minimum values. Similarly, the $\mathrm{Z}$ field shows a small maximum at ANC and a large minimum at ALC.

Figure 2 shows the charts of the $\mathrm{X}, \mathrm{Y}$ and $\mathrm{Z}$ variations at ALC and ANC for the period 21-30 April 1994. It is

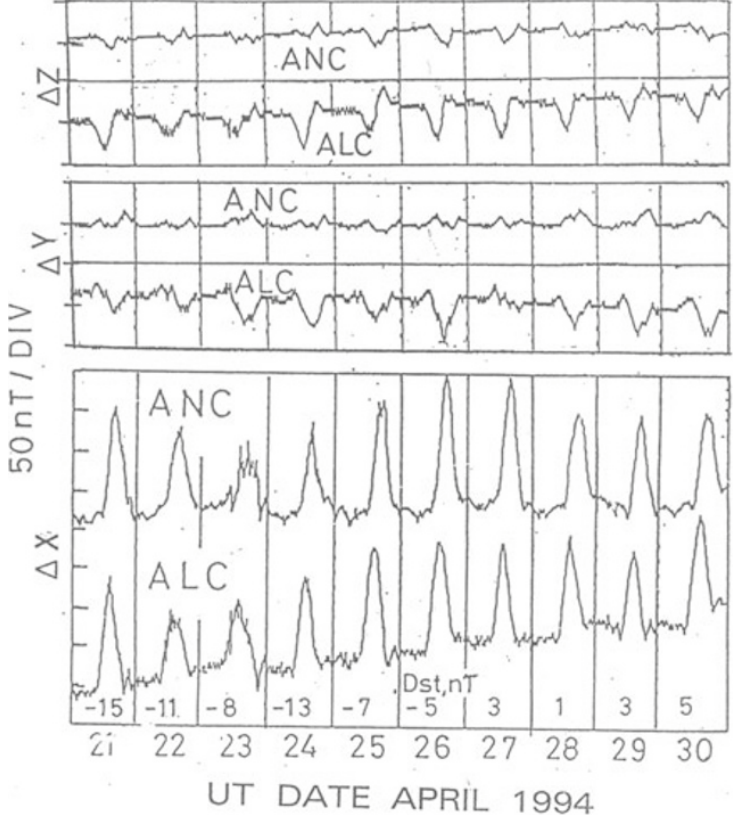

Fig. 2. Daily variation in the geomagnetic $\mathrm{X}, \mathrm{Y}$ and $\mathrm{Z}$ fields at Ancon (ANC) and Alcantra (ALC) during the period 21-30 April 1994.
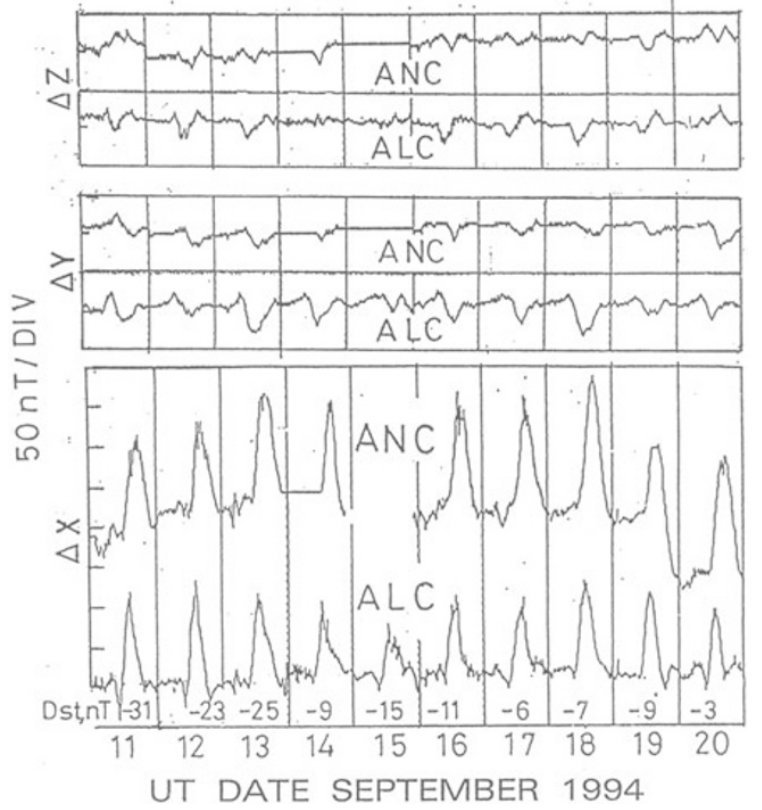

Fig. 3. Daily variation in the geomagnetic $\mathrm{X}, \mathrm{Y}$ and $\mathrm{Z}$ fields at Ancon (ANC) and Alcantra (ALC) during the period 11-20 September 1994.

again seen that the variations in the amplitude of the daily variation of $\mathrm{X}$ were synchronous at the two stations. Large values around 26 October and smaller values on 22-23 October were observed at both stations. The $\mathrm{Y}$ component showed small positive deviations at ANC and large negative deviations at ALC. An abnormal large amplitude in $\mathrm{Y}$ on 26 October at ALC is associated with a corresponding large daily range of the $\mathrm{X}$ field. The $\mathrm{Z}$ component during this period shows small variations at ANC but very large decreases at ALC.

Figures 3 and 4 show the daily variations of $\mathrm{X}, \mathrm{Y}$ and $\mathrm{Z}$ at ANC and ALC during the period 21-30 September 

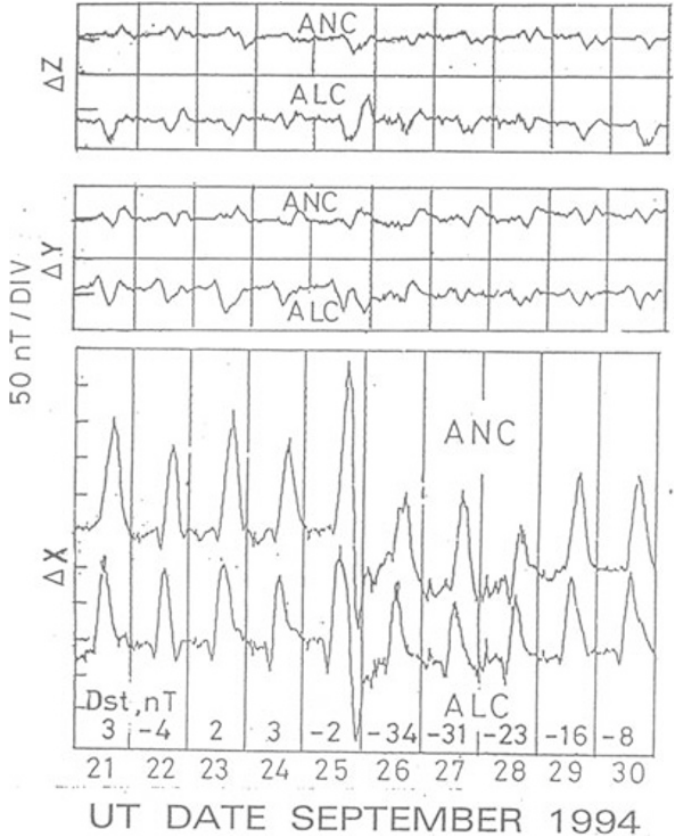

Fig. 4. Daily variation in the geomagnetic $\mathrm{X}, \mathrm{Y}$ and $\mathrm{Z}$ fields at Ancon (ANC) and Alcantra (ALC) during the period 21-30 September 1994.

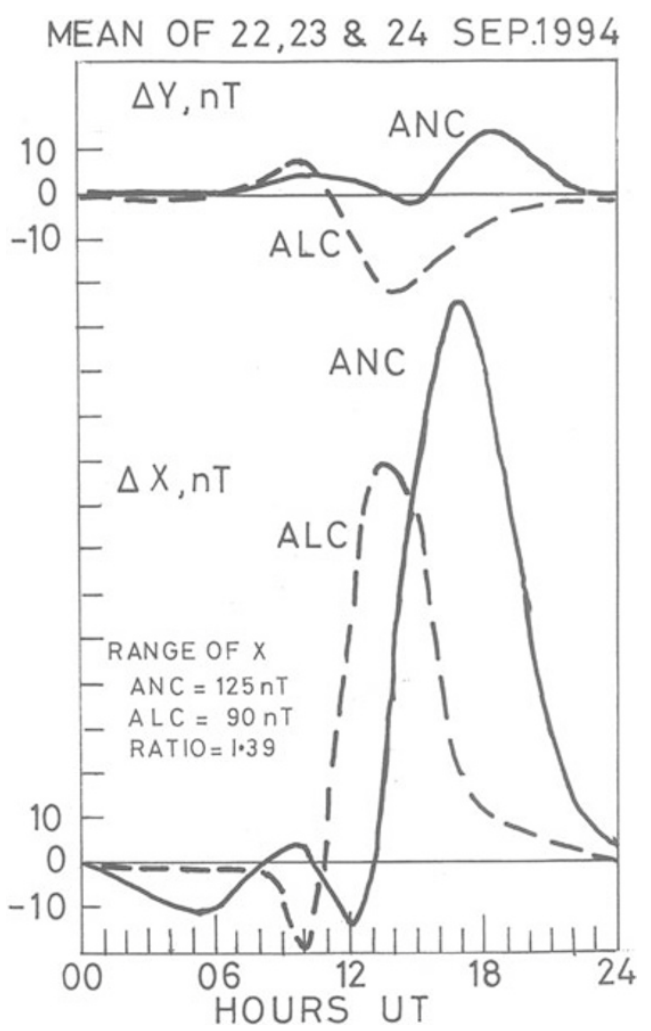

Fig. 5. Mean daily variations in the $\mathrm{X}$ and $\mathrm{Y}$ fields at Ancon (ANC) and Alcantra (ALC) averaged over 22, 23 and 24 September 1994.

1994. At ALC, a sharp decrease of X just before the start of the normal morning increase is an interesting feature to be studied and explained.

September 22, 23 and 24, 1994 were the quiet days of the month, and the monthly mean daily variations in the $\mathrm{X}$ and $\mathrm{Y}$ fields at ALC and ANC were computed; these

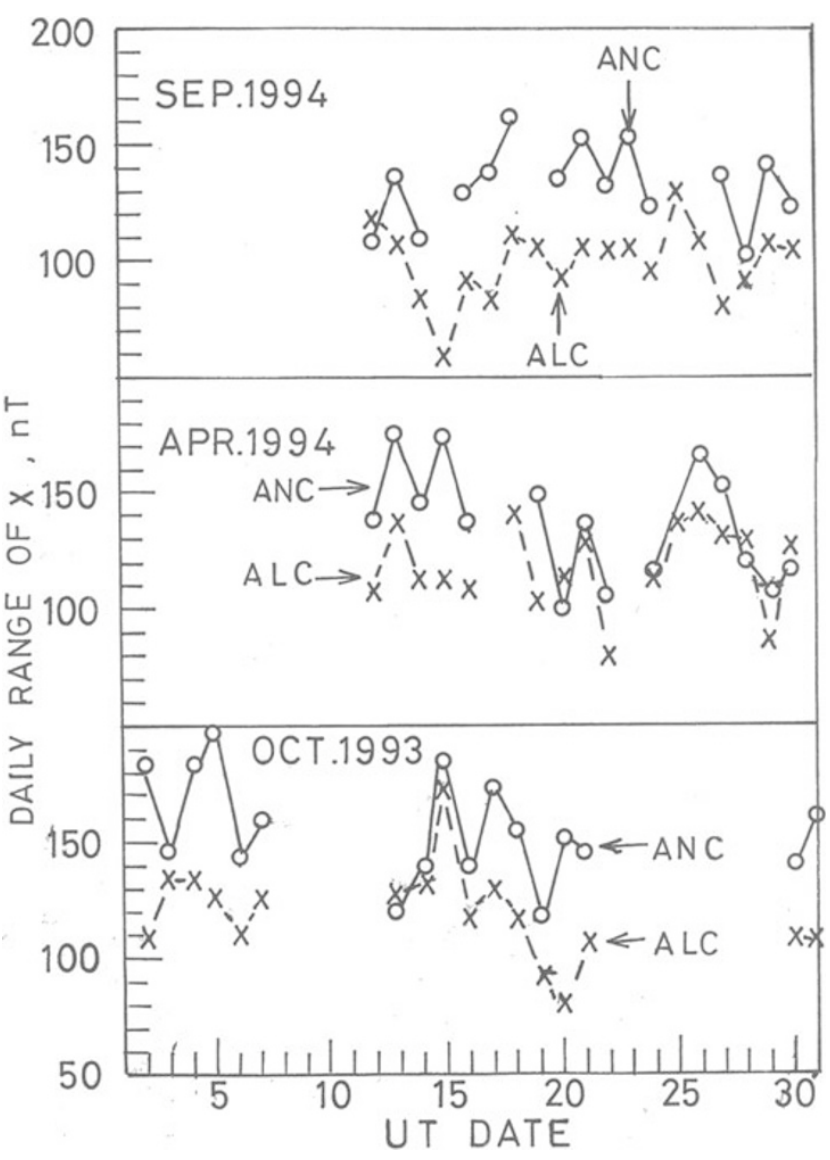

Fig. 6. Day-to-day variations in the daily range of the $\mathrm{X}$ field at Alcantra (ALC) and Ancon (ANC) during the months of October 1993, April 1994 and September 1994.

are shown in Fig. 5. The curves for ANC are seen to be shifted to later UT hours than those for ALC because ANC is about $2 \mathrm{~h}$ west of ALC. Significant short decreases of $\mathrm{X}$ are seen at both the stations just before the start of the normal daytime increase. The range of the X field was 125 $\mathrm{nT}$ at $\mathrm{ANC}$ and $90 \mathrm{nT}$ at ALC, which correspond to the range $\mathrm{H}$ of $125 \mathrm{nT}$ at $\mathrm{ANC}$ and $96 \mathrm{nT}$ at ALC. The daily variation in $\mathrm{Y}$ showed a short daytime maximum at ANC and a large daytime minimum at ALC.

An unusual large increase in $\mathrm{X}$ at $17 \mathrm{UT}$, which corresponds to noon, was observed at ANC and ALC without any short-period fluctuations. An examination of the IMF parameters indicated an abnormally large $B_{X}$ equal to +27 nT, with $B_{\mathrm{Y}}$ and $B_{\mathrm{Z}}$ being close to $0 \mathrm{nT}$ at $1930 \mathrm{UT}$. This large $\Delta \mathrm{X}$ was accompanied by a large increase in $\mathrm{Y}$ at ALC and a large decrease at ANC. This unusual event should be explored in more detail in a future investigation.

The daily range of $\mathrm{X}$, excluding the early morning dip, was $125 \mathrm{nT}$ at ANC and $90 \mathrm{nT}$ at ALC, giving a ratio of 1.39. This corresponds to the ratio of range $\mathrm{H}$ at $\mathrm{ANC}$ to that at ALC of 1.30. The Y field showed a midday maximum at ANC and a large midday minimum at ALC. Thus, the current vector during noon was inclined southward in Peru and northward in Brazil. It has to be noted that the declination in Brazil was $20^{\circ}$ west of North. This suggests that the midday $\mathrm{H}$ vector aligns itself to the dip declination rather than to the geographic meridian. 


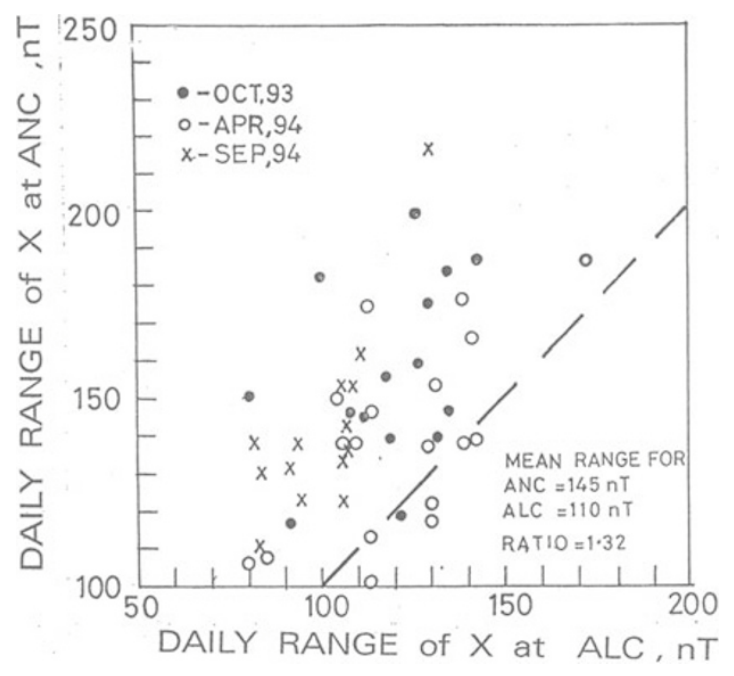

Fig. 7. Daily range of $\mathrm{X}$ at Ancon (ANC) on a number of days in October 1993, April 1994 and September 1994 against the corresponding value at Alcantra (ALC).

\subsection{Day-to day variation of range $X$}

The amplitudes of the daily range of $\mathrm{X}$ were computed for clear traces with little disturbances and the variations of these range $\mathrm{X}$ values at the two stations during the months of October 1993 and March and September 1994; these are shown in Fig. 6. The range $\mathrm{X}$ is generally larger at ANC than at ALC. A second and more important fact is that the day-to-day variations in range $\mathrm{X}$ showed a good correlation.

Figure 7 shows the mass plot of the amplitude of range $\mathrm{X}$ at ANC against the same at ALC. Most of the points indicate that the amplitude is greater at ANC than at ALC. The mean of all points yielded a value of range X of $145 \mathrm{nT}$ for ANC and $110 \mathrm{nT}$ for ALC. This corresponds to mean range $\mathrm{H}$ of $145 \mathrm{nT}$ at $\mathrm{ANC}$ and of $107 \mathrm{nT}$ at ALC. Thus, the ratio of range $\mathrm{H}$ at $\mathrm{ANC}$ to $\mathrm{ALC}$ would be 1.24.

\section{Discussion}

Chapman (1951) had assumed the $\mathrm{H}$ field to be northward so that the declination was zero. Baker and Martyn (1953) similarly assumed the tidal electric field to be along the E-W direction and that its action on the northward magnetic field $\mathrm{H}$ produced the vertical currents. The vertical polarization field developed due to the inhibition of vertical currents (conducting region bounded) that abnormally increased the eastward electric conductivity in the ionosphere over the dip equator. Rastogi (1962) suggested that the Cowling conductivity may be larger at stations with lower magnetic field strength. This could explain the highest electrojet current at Huancayo, which had the lowest magnetic field of all electrojet stations.

Rastogi (1993) argued that ( $\mathrm{H}$ observed at ground level is due to the overhead ionospheric current, which in turn is proportional to the product of $\mathrm{E}$ region ionization density and the horizontal electric field. He suggested an index of electric field $E\left(E=k \Delta \mathrm{H} / N_{m E}\right)$. He also showed that the solar cycle variation of $\Delta \mathrm{H}$ is directly related to the similar variation of $N_{m E}$ but that the seasonal variation of $\Delta \mathrm{H}$ is related to the corresponding variation in the electric field. The daily variation of $\Delta \mathrm{H}$ is related to the variation of both electron density and the electric field. The longitudinal variation in the daily range in $\mathrm{H}$ was attributed to the corresponding variation in the local electric field in the ionosphere.

The present analysis shows that the equatorial electrojet current is significantly larger in Peru $\left(75^{\circ} \mathrm{W}\right.$ longitude) than in Brazil within a separation of $2 \mathrm{~h}$ in local time. The total geomagnetic intensity is practically identical at the two places. Thus, the argument that the total ionospheric conductivity over the dip equator is inversely related to the total geomagnetic field intensity is not a valid reason for explaining the longitudinal variation of the equatorial electrojet current strength. The longitudinal variation in the strength of the equatorial electrojet current is suggested as the variation in ionospheric conductivity.

The noontime direction of the horizontal field, $\mathrm{H}$, aligns itself along the magnetic dip declination, suggesting the large inclination of the ionospheric current loop at low latitudes. One hypothesis is that this is due to a significant trans-equatorial ionospheric current. The direction of this meridional current varies significantly with longitude and, possibly, with the local time and season at the station.

A study of the solar flare and SC effects on the equatorial electrojet current at different equatorial stations may reveal the fine structures of the equatorial electrojet at different longitudes.

Acknowledgments. One of the authors (R. G. Rastogi) expresses his gratitude to the Indian Space Research Organisation, Bangalore for the granting of a research project and the Physical Research Laboratory, Ahmedabad for facilities for conducting these studies. We thank Prof. H. Chandra for his suggestions and assistance during the course of work. The authors also thank the referees for their useful suggestions.

\section{References}

Appleton, E. V., Two anomalies in the ionosphere, Nature, 157, 691, 1946. Baker W. G. and D. F. Martyn, Electric currents in the ionosphere, Philos. Trans. Roy. Soc. London, Ser. A. 246, 281-294, 1953.

Chapman, S., The equatorial electrojet as detected from the abnormal electric current distribution above Huancayo, Peru and elsewhere, Arch. Meterol. Geophys. Bioklimatol., A4, 368-390, 1951.

Cowling, T. G. and R. Borger, Electrical conductivity of the ionospheric D region, Nature, 162, 143, 1948.

Rastogi, R. G., The diurnal development of the anomalous equatorial belt in the F2 region of the ionosphere, J. Geophys. Res., 64, 727-732, 1959.

Rastogi, R. G., The morphology of lunar semi-diurnal variation in $\mathrm{f}_{\mathrm{o}} \mathrm{F}_{2}$ near solar noon, J. Atmos. Terr. Phys., 22, 290-297, 1961.

Rastogi, R. G., Enhancement of the lunar tide in the noon critical frequency of the $\mathrm{F}_{2}$ layer over the magnetic equator, J. Res. (NBS), 66D, 601-606, $1962 \mathrm{a}$.

Rastogi, R. G., Longitudinal variation in the equatorial electrojet, J. Atmos. Terres. Phys., 24, 1031-1040, 1962 b.

Rastogi R. G., Geomagnetic field variations at low latitudes and ionospheric electric fields, J. Atmos. Terres. Phys., 55, 1375-1381, 1993.

R. G. Rastogi (e-mail: profrgrastogi@yahoo.com) and K. Yumoto 